\title{
Presence of leptospires on genital tract of mares with reproductive problems
}

\author{
Camila Hamond ${ }^{\mathrm{a}}$, Cristiane P. Pestana ${ }^{\mathrm{b}}$, Cláudio Marcos Rocha-de-Souza ${ }^{\mathrm{b}}$, \\ Luis Eduardo R. Cunha ${ }^{\mathrm{c}}$, Felipe Z. Brandão ${ }^{\mathrm{d}}$, Marco Alberto Medeiros ${ }^{\mathrm{b}}$, \\ Walter Lilenbaum ${ }^{\mathrm{a}, *}$ \\ ${ }^{a}$ Laboratory of Veterinary Bacteriology, Department of Microbiology and Parasitology, Universidade Federal Fluminense, Niterói, Rio de Janeiro, Brazil \\ ${ }^{\mathrm{b}}$ Bio-Manguinhos, Fundação Oswaldo Cruz, Brazilian Ministry of Health, Rio de Janeiro, Rio de Janeiro, Brazil \\ ${ }^{\mathrm{c}}$ Instituto Vital Brazil, Niterói, Rio de Janeiro, Brazil \\ d Department of Pathology and Clinical Veterinary, Veterinary School, Faculty of Veterinary Medicine, Universidade Federal Fluminense, Niterói, Rio de Janeiro, \\ Brazil
}

\section{A R T I C L E I N F O}

\section{Article history:}

Received 14 January 2015

Received in revised form 20 June 2015

Accepted 25 June 2015

\section{Keywords:}

Leptospira

Uterus

Horse

\begin{abstract}
A B S T R A C T
Leptospirosis is a zoonotic disease of global importance, and has a worldwide distribution. Equine leptospirosis is commonly manifested by recurrent uveitis, reproductive disorders, as abortions, embryonic absorption, stillbirth and the birth of weak foals. The aim of this study was to verify the presence of Leptospira sp or its DNA in genital tract of mares with reproductive problems. A total of 38 mares with reproductive problems were studied. All the mares were sampled for blood (for serology), urine (for culturing and qPCR), vaginal fluid-VF and endometrial biopsy-EB (for culturing, qPCR and indirect immunofluorescence). PCRs products were sequenced for $\sec Y$ gene. Seventeen (44.7\%) serum samples were reactive, predominantly against serogroups Australis (76.4\%) and Pomona (23.6\%). No positive culture was obtained, but DNA was detected by qPCR on urine samples (26.3\%), VF (44.7\%) and EB (18.4\%) collected 2 months or longer following diagnosis of early fetal death and endometritis. Leptospira cell aggregations were visible by indirect immunofluorescence on $57.1 \%$ (4/7) EBs and $17.6 \%(3 / 17)$ VFs. A total of 18 amplicons showed interpretable sequences. Out of those 18 amplicons, 15 presented $100 \%$ of identity with the species L. interrogans (sv Bratislava and Pomona), while three were L. borgpertersenii. This study suggests the presence of leptospires in the uterus of mares with reproductive problems. Moreover, serology was shown not to be indicated for the diagnosis of presumptive Leptospira infection in early gestation. The most common agent of the genital infection in those mares was L. interrogans, most probably sg Australis.
\end{abstract}

(c) 2015 Elsevier B.V. All rights reserved.

\section{Introduction}

Equine leptospirosis is commonly manifested by recurrent uveitis and reproductive disorders, as abortions, embryonic absorption, stillbirth or neonatal mortality and the birth of weak foals (Ellis, 2015). The mechanisms involved in leptospiral pathogenesis are not well elucidated (Adler, 2014). Although leptospires are usually reported colonizing the kidneys, it has been demonstrated that they can also be present in the genital tract of cattle and small ruminants, leading to reproductive problems (Arent et al., 2013; Ellis and Thiermann, 1986; Farina et al., 1996). In mares, evidence of leptospiral DNA in vaginal fluid was recently

\footnotetext{
* Corresponding author. Fax: +55 2126292435.

E-mail address: mipwalt@vm.uff.br (W. Lilenbaum).
}

reported by our group (Hamond et al., 2014). Furthermore, the presence of leptospiral DNA was also found in the placenta and fetal fluids contained in the uterus of mares (Donahue and Williams, 2000; Erol et al., 2014). However, leptospiral DNA has never been reported in uterus samples, and it is uncertain if its presence on vaginal fluid is of genital or urinary origin.

Although late-term abortion is the most commonly reported aspect of equine reproductive leptospirosis, the infection may also lead to other reproductive problems such as early embryonic death (Pinna et al., 2014). Endometritis, mainly its subclinical form, is a major cause of infertility in the mare and it is influenced by the pathogen's type and the mare's subsequent immunological response (Buczkowska et al., 2014). Although never reported in equine leptospirosis, endometritis has been associated to leptospirosis in cows (Gonzalez et al., 1985). 
In this context, the aim of this study was to verify the presence of Leptospira sp or its DNA in genital tract of mares with reproductive problems.

\section{Material and methods}

\subsection{Animals}

Of the 206 horses ( 6 stallions, 105 mares and 95 foals), thirtyeight mares (4-21 y) of different races with reproductive problems were studied, all from the same farm in Rio de Janeiro, Brazil. As inclusion criteria, all the studied mares had presented reproductive problems repeat breeding, endometritis, early embryonic death ( $\leq 45$ days of pregnancy] or abortion [from 45 days to term]) during the last breeding season (October 2013-April 2014). The samples were collected from July to August (2014) in the period of anestrus. All mares were vaccinated against herpesvirus only. Additionally, during the study, no specific treatment for leptospirosis was conducted.

Mares were teased daily from the beginning of the breeding season for detection of estrus; once the estrus was detected they were daily submitted to rectal palpation for monitoring of follicular growth. The insemination took place when the mare presented ovarian follicle with $3.5 \mathrm{~cm}$ in diameter. For semen collection, artificial vagina method, following Botucatu model (Biotech Botucatu/ME Ltd., Botucatu, SP, Brazil) was employed. After collection, semen was evaluated for motility, vigor and sperm concentration. Semen was diluted with extender Botu-semen $\odot$ (Biotech Botucatu, Botucatu, SP, Brazil), in a final concentration of 800 million sperm per insemination dose $(20 \mathrm{~mL})$. Insemination was performed on alternate days until the verification of ovulation. Semen wasn't tested for the presence of Leptospira or its DNA.

Reproductive tract examinations were done with transrectal palpation and ultrasound (US) (Aloka SSD-500, Aloka Co., Ltd., Tokyo, Japan). Mares were examined after insemination when necessary by ultrasonography during the post breeding period, and at approximately $12,30,45,60,90,180$, and 270 days of pregnancy. Embryonic death and endometritis were detected by US. The first was determined by a positive result followed by a negative result in between 12 and 45 days post insemination. The later was determined by the presence of fluid in the uterus.

Two months after the end of the breeding season (June 2014), blood (serology), urine (culturing and qPCR), and vaginal fluid/ endometrial biopsy (culturing, qPCR and direct immunofluorescence-DI) were obtained from all the mares (Table 1 ).

\subsection{Collection and processing samples}

Blood-blood samples were collected into evacuated tubes (Vacutainer ${ }^{\circledR}$, BD Diagnostics, Franklin Lakes, USA) by jugular venipuncture. All samples were refrigerated and transported to the Leptospirosis Laboratory of Universidade Federal Fluminense, Niteroi, RJ, Brazil, to be tested as a batch.

Endometrial biopsy (EB)-prior to sample collection, the mare's tail was bandaged, and the vulva and perineum were cleaned and dried with a paper towel. Endometrial biopsy was collected using alligator-jawed (rounded) biopsy forceps $55-70 \mathrm{~cm}$ in length with a basket $20 \times 4 \times 3 \mathrm{~mm}$ in size (Biotech ${ }^{\circledR}$, Botucatu, SP, Brazil), and taken from the base of the uterine horn (Buczkowska et al., 2014). The biopsy forceps was washed with running water and soap and kept in Kilol-L solution, according to the recommendations of the manufacturer, in between each collection (Quinabra, Qúimica Natural Brasileira LTDA-São José dos Campos, SP-Brazil). After collection it was flambéed with alcohol 70\% (Rioumina, São Paulo, SP-Brazil), and then cooled with sterile saline. Each sample was divided into two parts. The first was immediately inoculated into
$5 \mathrm{~mL}$ of culture media (EMJH) and the other one was used for DIimprints (Chagas-Junior et al., 2012) and then kept in a $2 \mathrm{~mL}$ tube containing $1 \mathrm{~mL}$ of RNAlater (Ambion, Huntingdon, UK) for DNA extraction (qPCR).

Vaginal fluids (VF)-immediately after biopsy collection, the vulva and perineum were cleaned once more and VF was collected from each mare using three commercially available Cytology Brushes (CB-PlasticWay ${ }^{\mathbb{R}}$, São Paulo, Brazil). While one CB was immediately inoculated into $5 \mathrm{~mL}$ of culture media (culturing), the other two were transferred to $15 \mathrm{~mL}$ sterile vials (BD, Franklin Lakes, USA) containing $5 \mathrm{~mL}$ of stock media (Saline solution $0.15 \mathrm{M}$, TrisHCl pH7.6 and BSA 2\%), for DI and qPCR.

At the laboratory, VF from stock media was centrifuged $16,000 \mathrm{~g}$ for $20 \mathrm{~min}$, the supernatant was discarded and pellet was resuspended with $200 \mu \mathrm{L}$ of PBS. VF smears (duplicate) for imprint were prepared by placing $100 \mu \mathrm{L}$ of VF onto a poly-L-lysine-coated glass slide (Pinne and Haake, 2011). Imprint slides were dried at room temperature and fixed in 1\% formaldehyde for $3 \mathrm{~min}$.

Urine-after collection of VF urine samples were collected by probing. Urine was collected in $50 \mathrm{~mL}$ sterile vials (BD, Franklin Lakes, USA) and immediately inoculated into $5 \mathrm{~mL}$ of culture media (EMJH). A $2 \mathrm{~mL}$ aliquot was refrigerated and transported to the laboratory for qPCR.

\section{Table 1}

Reproductive problems, serology (MAT), qPCR and Indirect immunofluorescence assay (IFA) results on 38 mares with reproductive problems studied for leptospirosis in Rio de Janeiro, Brazil.

\begin{tabular}{|c|c|c|c|c|c|c|c|}
\hline \multirow[t]{2}{*}{ ID } & \multirow[t]{2}{*}{ Reproductive problem } & \multirow[t]{2}{*}{ MAT } & \multicolumn{3}{|c|}{ qPCR } & \multicolumn{2}{|l|}{ IFA } \\
\hline & & & EB & VF & $\mathrm{U}$ & EB & VF \\
\hline 1 & Early embryonic death & + & - & + & - & ND & - \\
\hline 2 & Endometritis & + & - & - & - & ND & ND \\
\hline 3 & Endometritis & - & - & + & - & ND & - \\
\hline 4 & Endometritis & + & - & - & + & ND & ND \\
\hline 5 & Early embryonic death & - & - & + & - & ND & - \\
\hline 6 & Repeat breeding & + & - & - & - & ND & ND \\
\hline 7 & Early embryonic death & + & - & + & + & ND & - \\
\hline 8 & Early embryonic death & - & - & - & - & ND & ND \\
\hline 9 & Early embryonic death & - & - & - & - & ND & ND \\
\hline 10 & Repeat breeding & - & + & + & - & + & ND \\
\hline 11 & Endometritis & - & + & + & - & + & + \\
\hline 12 & Endometritis & - & + & + & - & - & - \\
\hline 13 & Endometritis & - & + & + & - & - & - \\
\hline 14 & Early embryonic death & + & - & - & - & ND & ND \\
\hline 15 & Endometritis & + & + & + & - & + & - \\
\hline 16 & Abortion & + & + & + & + & ND & - \\
\hline 17 & Repeat breeding & - & - & - & - & ND & ND \\
\hline 18 & Early embryonic death & - & - & + & - & ND & - \\
\hline 19 & Early embryonic death & + & - & - & - & ND & ND \\
\hline 20 & Endometritis & - & + & + & + & + & - \\
\hline 21 & Repeat breeding & - & - & - & - & ND & ND \\
\hline 22 & Early embryonic death & - & - & - & - & ND & ND \\
\hline 23 & Repeat breeding & - & - & - & - & ND & ND \\
\hline 24 & Early embryonic death & + & - & - & + & ND & ND \\
\hline 25 & Endometritis & + & - & + & + & ND & - \\
\hline 26 & Repeat breeding & - & - & - & - & ND & ND \\
\hline 27 & Repeat breeding & - & - & - & - & ND & ND \\
\hline 28 & Early embryonic death & + & - & - & - & ND & ND \\
\hline 29 & Early embryonic death & + & - & - & - & ND & ND \\
\hline 30 & Endometritis & - & - & + & + & ND & + \\
\hline 31 & Early embryonic death & + & - & - & + & ND & ND \\
\hline 32 & Endometritis & + & - & - & + & ND & ND \\
\hline 33 & Early embryonic death & - & - & + & - & ND & - \\
\hline 34 & Endometritis & + & - & + & - & ND & - \\
\hline 35 & Endometritis & + & - & - & - & ND & ND \\
\hline 36 & Early embryonic death & - & - & + & - & ND & - \\
\hline 37 & Endometritis & - & - & - & - & ND & ND \\
\hline 38 & Repeat breeding & + & - & - & + & ND & ND \\
\hline
\end{tabular}

+ Positive, - Negative, ND-not determined. 


\subsection{Serology}

Leptospira specific antibodies, microscopic agglutination test (MAT) was used with a complete panel including 28 serovars representing 24 serogroups (sg), according to international standards (OIE, 2012). The serum samples were initially diluted at $1: 50$ using $100 \mu \mathrm{L}$ of serum and $4900 \mu \mathrm{L}$ of phosphate buffered saline (SSTF) (pH 7.6). A $50 \mu \mathrm{L}$ of the diluted serum was distributed in microplates and $50 \mu \mathrm{L}$ of the serovar was added. Finally, twofold serial dilutions were carried out. The presumptive infective serovar was considered the one which presented the highest titer. Serum samples were considered reactive when reached titres $\geq 200$.

\subsection{Bacterial isolation}

Three drops of each urine sample, $\mathrm{CB}$ and $\mathrm{EB}$ were inoculated into $5 \mathrm{~mL}$ of EMJH (BD Difco, Franklin Lakes, NJ, USA). Tubes were incubated at $28^{\circ} \mathrm{C}$ for 30 weeks, and examined weekly in dark field microscopy (OIE, 2012).

\subsection{Quantitative polymerase chain reaction ( $q P C R$ )}

The TaqMan qPCR assay used in this study was designed to identify the LipL32 gene and was performed by extraction of DNA with the QIAamp DNA Mini Kit ${ }^{\circledR}$ (Qiagen, Valencia, CA, USA), as the manufacturer's instructions.

A $87 \mathrm{bp}$ region of LipL32 gene was amplified using primers (forward primer, 5'- TTGGATCCGTGTAGAAAGAATGTC $-3^{\prime}$; reverse primer, $5^{\prime}$ - TCGTCCAATTTTTGAACTGGTTT $-3^{\prime}$ ). and probe (FAM $5^{\prime}-$ CCAAATCGCCAAAGCTGCGAAAGC - 3'/ZEN/IowaBlack) designed by Primer Express 3.0 program based on the consensus sequences formed by the alignment (MegAlign Lasergene software/Version 5.5; DNASTAR ${ }^{\circledR}$ ) of 6 pathogenic species (GenBank accession numbers acession BD134126, СР000350, CP000348, AY609326,
AF181556, AF181555, AY609331, AE016823). Specificity of primers and probe was confirmed by BLAST (http://blast.ncbi.nlm.nih.gov/).

The $20 \mu \mathrm{L}$ reaction was conducted on a StepOne Real Time PCR System, with default cycling conditions (Life Technologies, Carlsbad, CA, USA) containing $6 \mu \mathrm{L}$ of template, $0.6 \mu \mathrm{L}(300 \eta \mathrm{M})$ of each primer and $2 \mu \mathrm{L}(250 \eta \mathrm{M})$ of probe (Integrated DNA Technologies), $10 \mu \mathrm{L}$ of TaqMan ${ }^{\circledR}$ Universal Master Mix II (Life Technologies, Carlsbad, CA, USA) and $0.8 \mu \mathrm{L}$ of DEPC treated water (Life Technologies Carlsbad, CA, USA). All reactions were performed in triplicate, including a positive control (Leptospira interrogans serovar L1-130) and a negative control (DEPC treated water/Life Technologies Carlsbad, CA, USA)

To perform a standard curve, the entire $L$. interrogans serovar L1-130 LipL32 gene was cloned using the pVAX1 Vector (Life Technologies Carlsbad, CA, USA.), and the plasmidial construction was denoted as PVAXHap. Plasmids were isolated with Qiaprep Plasmid Maxiprep kit (QIAGEN, Valencia, CA, USA) and DNA concentrations were determined by Qubit 2.0 fluorometry using Qubit ${ }^{\circledR}$ dsDNA BR Assay Kit (Life Technologies Carlsbad, CA, USA). . The assay detection limit was obtained using a 10 -fold serial dilution of PVAXHap (3-3 $\times 10^{5}$ genome copies), and it was determined to be 3 genome copies per PCR volume, a high analytic sensitivity.

\section{6. $P C R$ secY and sequencing}

For sequencing, PCR directed towards the $\sec Y$ gene was conducted. DNA was amplified using Platinum ${ }^{\mathbb{R}}$ Taq polymerase High Fidelity (Invitrogen ${ }^{\mathrm{TM}}$, Carlsbad, CA, USA) under standard conditions. A portion of the $\sec Y$ gene was amplified with the primers previously described (N. Ahmed et al., 2006), while the used protocol followed Bourhy et al. (2013). The amplicons were sequenced in both directions using Big Dye Terminator 3.1 cycle sequencing Kit (Life Technologies, Foster City, USA) on ABI 3500 XL Genetic Analyzer (Life Technologies, Carlsbad, CA, USA). All molecular epidemiological data were stored and analyzed with
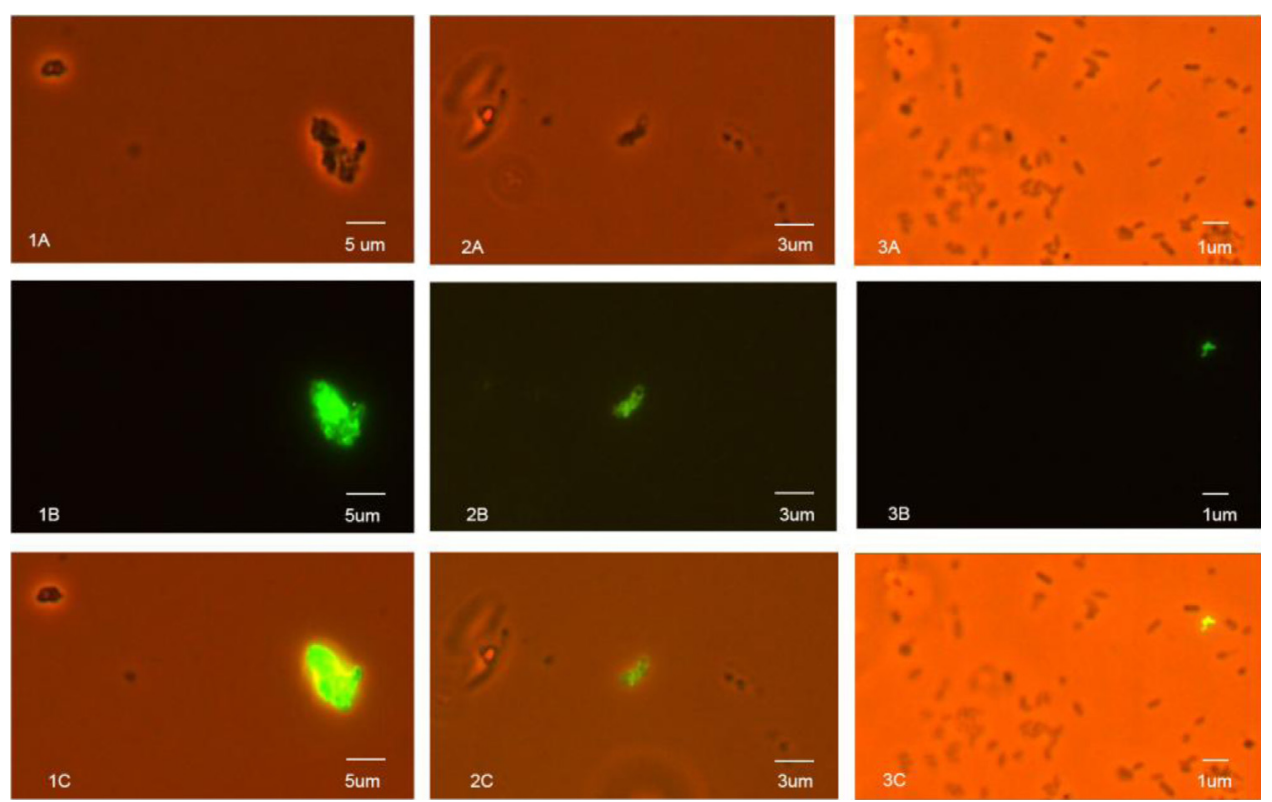

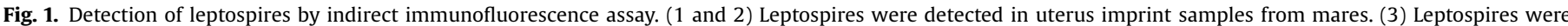

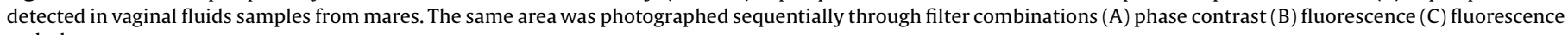
and phase contrast 
DNAStar Software Lasergene (Version 5.05; DNASTAR ${ }^{\circledR}$ ). Sequences were compared with four available sequences (NCBI) reference strains and one local isolate (L. interrogans sg Australis-2013_SU5) (Hamond et al., 2015). The tree was drawn using the unweighted pair-group method with arithmetic average (UPGMA) algorithm.

\subsection{Indirect immunofluorescence assay (IFA)}

IFA was carried out on VF and EB samples as previously described (Pinne and Haake, 2011), and conducted only on those samples that were qPCR positives. After fixed with $1 \%$ formaldehyde, imprint slides were incubated for $1 \mathrm{~h}$ at $37^{\circ} \mathrm{C}$ with a primary rabbit polyclonal anti-rLipL32 antibody (1:500) or with a rabbit preimmune serum (1:500; used as negative control), followed by three washes with 3\% PBS-BSA pH7.4. Finally, imprints were incubated with Alexa Fluor $\AA 488$ goat anti-rabbit $\operatorname{IgG}(\mathrm{H}+\mathrm{L})$ $(1: 2,000)$ for $1 \mathrm{~h}$ at $37^{\circ} \mathrm{C}$ and washed three times with $3 \%$ PBS-BSA pH7.4. Two hundred microliters of each VF sample were added into each well in the precoated poly-L-lysine-chamber slide (Nunc ${ }^{\mathrm{TM}}$ Lab-Tek $^{\mathrm{TM}}$ II Chamber Slide ${ }^{\mathrm{TM}}$ System) (Thermo Scientific, Waltham, MA, USA) and incubated for $1 \mathrm{~h}$ at $37^{\circ} \mathrm{C}$. Slides were fixed with $1 \%$ formaldehyde. Incubations with primary and secondary antibody were performed as described above. Both imprints and slides were dried for $15 \mathrm{~min}$ and assembled using coverslips and antifade (Prolong Gold antifade) (Life Technologies, Carlsbad, CA, USA). After $24 \mathrm{~h}$, the slides were sealed using colorless glaze and viewed under a microscope Axiolmager $\mathrm{m} 1$ (Zeiss) (Thornwood, NI, USA).

\subsection{Statistics}

Non-parametric data were analyzed by the chi-square test. Analysis was conducted using SPSS statistical software (SPSS Inc., Chicago, USA), and results were considered significant when $P<0.05$.

\section{Results}

Considering serology (MAT), 17/38 (44.7\%) serum samples were reactive. Serogroup Australis was the most frequent, being observed in $13(76.4 \%)$ reactions, while 4 (23.6\%) were reactive against serogroup Pomona. In relation to the titers, 12 (70.5\%) reached 200, and 5 (29.5\%), 400.

No positive culture was obtained for any of the tested samples. In contrast, 19 mares had at least one qPCR positive result (50\%). Considering the samples, 10 urines (26.3\%), 17 VFs (44.7\%) and 7 EBs (18.4\%) were qPCRpos. Only 2 of the 19 mares were qPCRpos in all the 3 samples. Seven mares presented leptospiral DNA only in $\mathrm{VF}$ and uterus; 7 presented it only in VF; 5 only in the urine. Leptospiral DNA detection in VF was strongly associated to uterus $(P<0.0001)$ and slightly to urine $(P=0.04)$.

It was also verified that, from the 10 mares that were qPCRpos on urine, 8 (80\%) were seroreactive, while from the 7 that were qPCRpos on EB, only 2 (28.6\%) were seroreactive, a strongly significant $(P=0.046)$ association.

The immunofluorescence assay showed cell aggregations on 4/ 7 EBs (57.1\%) and 3/17 VFs (17.6\%) (Fig. 1). No Leptospira cells neither cell aggregations were seen at EBs and at VFs incubated with preimune serum (data not shown).

A total of $18 \mathrm{sec} Y$ amplicons ( 8 from urine and 10 from VF) gave interpretable sequences (Fig. 2). From those, 15 shared very high identify with the species $L$. interrogans, while three were $L$. borgpertersenii. When comparing to the reference strains, 10 (U491/FV491, U457/FV457, FV728, U680/FV680, U499/FV499 and FV696) were very close (>99\%) to L. interrogans sv Australis and to $L$. interrogans sv Bratislava, as well as to a local L. interrogans sv Bratislava isolate obtained from swine (2013_SU5, GenBank KP263060). The remaining 5 sequences (FV643, FV642/U642, U704 and U732) of L. interrogans were closely related (99.9\%) to the reference isolate of sv Pomona (strain Kennewicki), which was first obtained from a horse in North America.

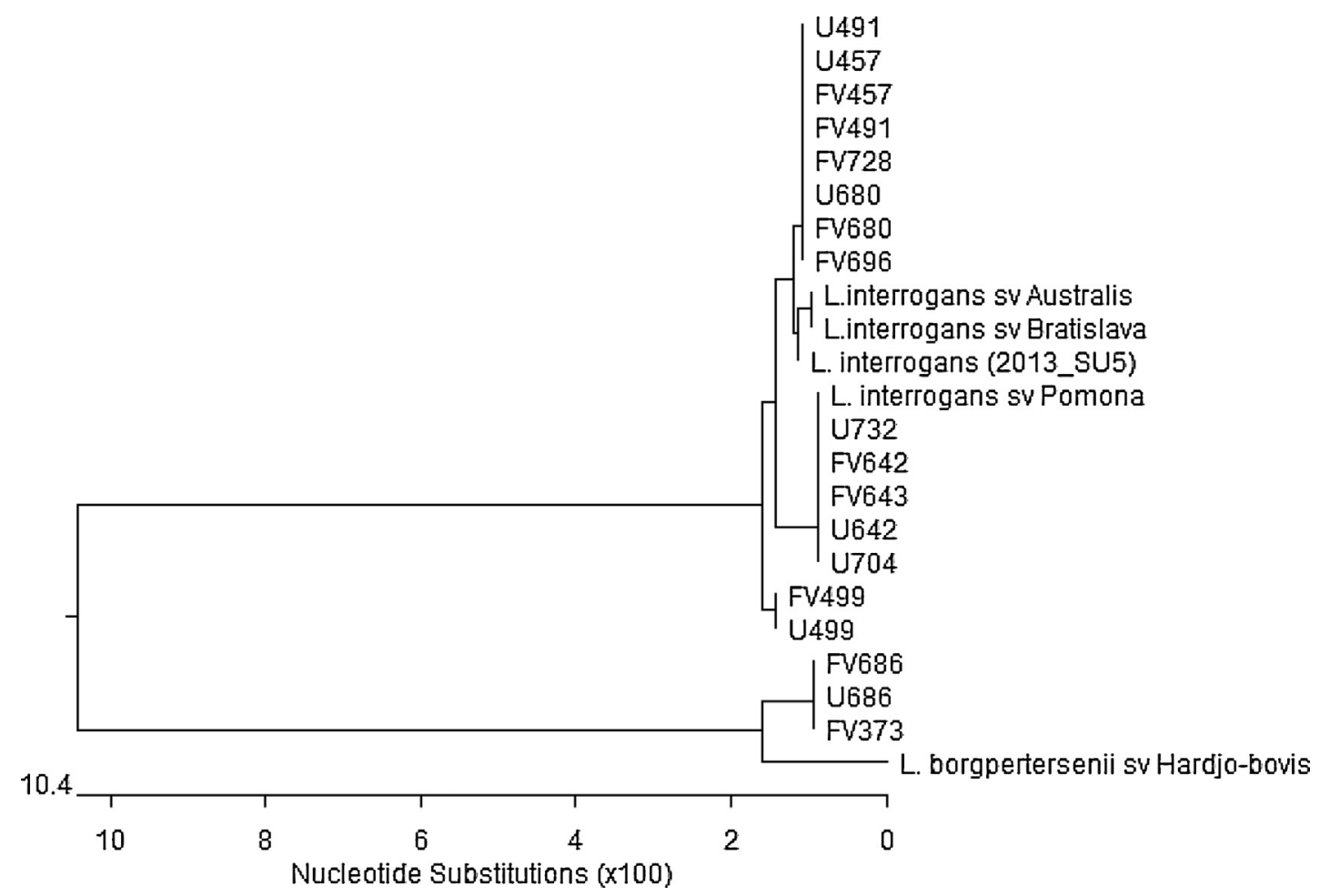

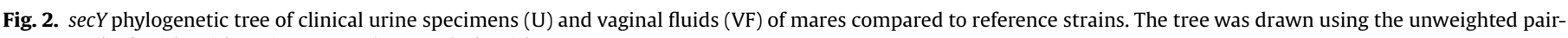
group method with arithmetic average (UPGMA) algorithm. 
Considering the 3 sequences that belong to the species $L$. borgpetersenii (FV686/U686 and FV373), all of them were identical among themselves and similar (98\%) to $L$. borgpertersenii sv Hardjobovis.

\section{Discussion}

Considering serological results, the high occurrence of Leptospira specific agglutinins in the studied mares was not unexpected, since Rio de Janeiro is an endemic region for leptospirosis and the studied group presented reproductive problems. Serogroup Australis is consistently predominant in other studies conducted on horses in Brazil (Hamond et al., 2014; Pinna et al., 2014) and is referred to be adapted to horses (Ellis and Thiermann, 1986). Moreover, seroreactivity against sg Pomona was also observed. Leptospira interrogans serovar Pomona is referred as an important serogroup in horses (Baird et al., 1972), having wildlife as its main reservoir (Timoney et al., 2011). In Brazil, the extension of Pomona distribution among wildlife is unknown.

Although the culture isolation is the gold standard for direct detection of leptospires in biological samples, none of the studied samples yielded pure cultures. This is most probably due to the well-known difficulties in obtaining leptospiral isolates, which are particularly more evident for serovar Bratislava, the most common serovar of sg Australis reported in horses (Ellis, 2015). Therefore, we believe that the failure in obtaining isolates is directly associated to the predominance of Bratislava among the studied mares as demonstrated by serology and sequencing of secY PCR products.

Due to its high sensitivity, specificity and speed of amplification, PCR has been shown to be extremely useful in detecting and identifying organisms in instances where existing culture techniques have failed or have been inadequate (Ahmed et al., 2009). In the present study, the qPCR results support this evidence as an effective method for detecting leptospiral DNA on urine, VF and uterus from horses. These results showed that the studied mares with reproductive problems were infected and Leptospira DNA was shared both in the urine and VF. Moreover, its presence was also showed by qPCR and IFA for the first time in uterus.

Few reports have suggested that uterine infection may occur on leptospirosis. This has been observed among cows (Ellis and Thiermann, 1986), small ruminants (Arent et al., 2013) and placenta and fetal fluids contained in the uterus of mares (Donahue and Williams, 2000; Erol et al., 2014). To the best of our knowledge, this is the first report showing the presence of Leptospira sp and its DNA on the uterus of mares with reproductive problems.

The origin of the leptospiral DNA that was detected in VF remains unclear. In the present study, it was more strongly associated to uterine infection, but a urinary origin for that finding cannot be excluded. In a recent study of our group, VF positivity at PCR was associated to urine (Hamond et al., 2014). Indeed, it is possible that VF positivity at qPCR may represent both urinary and uterine infection, and should be encouraged as a useful sample for leptospiral molecular testing.

Serology has severe limitations in the diagnosis of chronic infection in individual animals, both in the diagnosis of abortion and in the identification of renal or genital carriers where titers are falling or static (Ellis, 2015). In the present study it has been demonstrated that renal carriers are more often seroreactive (but not always), while genital carriers are more frequently seronegative. It is known that leptospires protect themselves against the host's innate immune system, a strategy that allows the bacteria to reach immunologically safe environments (Vieira et al., 2011). We suggest that, when located in the uterus, leptospires are more protected against the immune system of the host, leading to a weaker systemic humoral response. Therefore, serology has shown not to be an adequate method for detecting genital carriers, and molecular methods conducted on VF must be encouraged for the diagnosis of the reproductive syndrome of leptospirosis in mares. If the diagnosis relies exclusively on serology, many genital carriers would be misdiagnosed, what may in part explain the frustrating results on leptospirosis control programs.

Cell aggregation is believed to be an important mechanism of pathogenic leptospira to survive in different environments. Interestingly, since leptospires were visualized in uterus by IFA we cannot rule out that imprint of biopsy may not reflect what is present on the endometrial surface. Leptospires tend to form cell aggregates and not spread out on the endometrium. It has been suggested that the long-term colonization of mammalian maintenance host species by pathogenic leptospires proceed via the formation of cell aggregates in vitro and in vivo (Ristow et al., 2008; Brihuega et al., 2012). Also leptospiral auto-aggregation was demonstrated in the chronic colonization of renal tubules of rats (Athanazio et al., 2008), but that phenomena had never been demonstrated in uterus before. Few studies address the colonization pattern of leptospires in kidneys in horses, and studies of its presence on uterus are even scarcer. Nevertheless, these studies are of the fundamental importance, since they may elucidate questions on the chronic carriage of the pathogen in animal reservoirs. The determination of the structure and the mechanism of colonization in the animal reservoir is certainly of fundamental importance (Athanazio et al., 2008).

Sequencing has demonstrated that the majority of PCR products belong to the $L$. interrogans species, being similar to a reference strain of sv Bratislava, as well as to a local strain of sv Bratislava obtained from swine (Hamond et al., 2015). This finding agrees to the available seroepidemiological data regarding horses leptospirosis in the studied region which refers to Bratislava as a common serovar in Brazil (Hamond et al., 2014; Pinna et al., 2014). Nevertheless, although not frequently reported in local serosurveys, sv Pomona was also identified by sequencing of amplicons. That serovar, particularly the strain Kennewicki, has been reported as a cause of reproductive failures such as abortions or placentitis in North American (Erol et al., 2014) and it is maintained by other animal species, with mares being considered incidental hosts (Donahue and Williams, 2000). Curiously, 2 of the samples were $L$. borgpertersenii, an unexpected finding since this species is commonly associated to cattle (Fang et al., 2014), and not to horses. A possible infection source was the presence of sheep around the horses, but this hypothesis could not be confirmed since those sheep were not sampled. Unfortunately, none of the uterine PCR products gave interpretable sequences what could indicate more clearly the agent of the uterine infection. Nevertheless, since uterine PCR positivity was strongly associated to that of $\mathrm{VF}$, it is possible to infer that the agent of the uterine infection was the same that was evidenced on VF.

In conclusion, this study demonstrated the presence of leptospires in the uterus of mares with reproductive problems, reinforcing the importance of the presence of the agent on genital organs. Moreover, serology seems not to be indicated for the diagnosis of the genital infection, and qPCR of uterus should be encouraged. Based on $\sec Y$ sequence, the most common agent of the genital infection in those mares was L. interrogans, most probably sg Australis.

\section{Acknowledgements}

This study was supported by FAPERJ, CNPq and CAPES. WL, FZB and MAM are CNPq fellows. The authors thank Leonardo Galileu Meirelles (IVB) for his help on sampling, Prof. Dr. Rafael Hirata (UERJ) for his help in immunofluorescence, and G. Martins (UFF) for his help on statistics. 


\section{References}

Adler, B., 2014. Pathogenesis of leptospirosis: cellular and molecular aspects. Vet. Microbiol. 172, 353-358. doi:http://dx.doi.org/10.1016/j. vetmic.2014.06.015.

Ahmed, N., Devi, S.M., Valverde Mde, L., Vijayachari, P., Machang'u, R.S., Ellis, W.A. Hartskeerl, R.A., 2006. Multilocus sequence typing method for identification and genotypic classification of pathogenic Leptospira species. Ann. Clin. Microbiol. Antimicrob. 5, 28. doi:http://dx.doi.org/10.1186/1476-0711-5-28.

Ahmed, A., Engelberts, M.F.M., Boer, K.R., Ahmed, N., Hartskeerl, R.A., 2009. Development and validation of a real-time PCR for detection of pathogenic leptospira species in clinical materials. PLoS One 4, e7093. doi:http://dx.doi.org/ 10.1371/journal.pone.0007093.

Arent, Z., Frizzell, C., Gilmore, C., Mackie, D., Ellis, W.A., 2013. Isolation of Leptospires from genital tract of sheep. Vet. Rec. 173, 582. doi:http://dx.doi.org/10.1136/ vr.101969.

Athanazio, D.A., Silva, E.F., Santos, C.S., Rocha, G.M., Vannier-Santos, M.A., McBride, A.J.A., Ko, A.I., Reis, M.G., 2008. Rattus norvegicus as a model for persistent renal colonization by pathogenic Leptospira interrogans. Acta Trop. 105, 176-180. doi: http://dx.doi.org/10.1016/j.actatropica.2007.10.012.

Baird, J.D., Williams, T., Claxton, P.D., 1972. A premature birth associated with Leptospira pomona infection in a mare. Aust. Vet. J. 48, 524-526.

Bourhy, P., Herrmann Storck, C., Theodose, R., Olive, C., Nicolas, M., Hochedez, P., Lamaury, I., Zinini, F., Brémont, S., Landier, A., Cassadou, S., Rosine, J., Picardeau, M., 2013. Serovar diversity of pathogenic Leptospira circulating in the French West Indies. PLoS Negl. Trop. Dis. 7, e2114.

Brihuega, B., Samartino, L., Auteri, C., Venzano, A., Caimi, K., 2012. In vivo cell aggregations of a recent swine biofilm-forming isolate of Leptospira interrogans strain from Argentina. Rev. Argent. Microbiol. 44, 138-143.

Buczkowska, J., Kozdrowski, R., Nowak, M., Raś, A., Staroniewicz, Z., Siemieniuch, M. J., 2014. Comparison of the biopsy and cytobrush techniques for diagnosis of subclinical endometritis in mares. Reprod. Biol. Endocrinol.12, 27. doi:http://dx. doi.org/10.1186/1477-7827-12-27.

Chagas-Junior, A.D., da Silva, C.L.R., Soares, L.M., Santos, C.S., Silva, C.D.C.M. Athanazio, D.A., Reis, dos, M.G., McBride, F.W.C., McBride, A.J.A., 2012. Detection and quantification of Leptospira interrogans in hamster and rat kidney samples: immunofluorescent imprints versus real-time PCR. PLoS One 7, e32712. doi: http://dx.doi.org/10.1371/journal.pone.0032712.

Donahue, J.M., Williams, N.M., 2000. Emergent causes of placentitis and abortion. Vet. Clin. North Am. Equine Pract. 16, 443-456 viii.

Ellis, W.A., 2015. Animal leptospirosis. Curr. Top. Microbiol. Immunol. 387, 99-137. doi:http://dx.doi.org/10.1007/978-3-662-45059-8_6.
Ellis, W.A., Thiermann, A.B., 1986. Isolation of leptospires from the genital tracts of Iowa cows. Am. J. Vet. Res. 47, 1694-1696.

Erol, E., Jackson, C.B., Steinman, M., Meares, K., Donahoe, J., Kelly, N., Locke, S., Smith, J.L., Carter, C.N., 2014. A diagnostic evaluation of real-time PCR, fluorescent antibody and microscopic agglutination tests in cases of equine leptospiral abortion. Equine Vet. J. doi:http://dx.doi.org/10.1111/evj.12281 n/a-n/a.

Fang, F., Collins-Emerson, J.M., Cullum, A., Heuer, C., Wilson, P.R., Benschop, J., 2014 Shedding and seroprevalence of pathogenic Leptospira spp. in sheep and cattle at a New Zealand abattoir. Zoonoses Public Health doi:http://dx.doi.org/ 10.1111/zph.12146 n/a-n/a.

Farina, R., Cerri, D., Renzoni, G., Andreani, E., Mani, P., Ebani, V., Pedrini, A., Nuvoloni, R., 1996. Leptospira interrogans in the genital tract of sheep. Research on ewes and rams experimentally infected with serovar hardjo (hardjobovis). New Microbiol. 19, 235-242.

Gonzalez, H.E., Crowell, W.A., Caudle, A.B., Thompson, F.N., 1985. Morphometric studies of the bovine uterus: microscopic lesions and retrospective reproductive history. Am. J. Vet. Res. 46, 2588-2595.

Hamond, C., Martins, G., Loureiro, A.P., Bremont, S., Medeiros, M.A., Bourhy, P. Lilenbaum, W., 2015. First isolation and characterization of Leptospira interrogans serogroup Australis from swine in Brazil. Braz. J. Vet. Res. 35, 6-8.

Hamond, C., Pinna, A., Martins, G., Lilenbaum, W., 2014. The role of leptospirosis in reproductive disorders in horses. Trop. Anim. Health. Prod. 46,1-10. doi:http:// dx.doi.org/10.1007/s11250-013-0459-3.

Pinna, A., Martins, G., Hamond, C., Medeiros, M.A., de Souza, G.N., Lilenbaum, W., 2014. Potential differences between Leptospira serovars, host-adapted (Bratislava) and incidental (Copenhageni), in determining reproductive disorders in embryo transfer recipient mares in Brazil. Vet. Rec. 174, 531. doi: http://dx.doi.org/10.1136/vr.101444.

Pinne, M., Haake, D., 2011. Immuno-fluorescence assay of leptospiral surfaceexposed proteins. J. Vis. Exp. doi:http://dx.doi.org/10.3791/2805 e2805-e2805.

Ristow, P., Bourhy, P., Kerneis, S., Schmitt, C., Prevost, M.-C., Lilenbaum, W., Picardeau, M., 2008. Biofilm formation by saprophytic and pathogenic leptospires. Microbiology (Reading, Engl.) 154, 1309-1317. doi:http://dx.doi. org/10.1099/mic.0.2007/014746-0.

Timoney, J.F., Kalimuthusamy, N., Velineni, S., Donahue, J.M., Artiushin, S.C., Fettinger, M., 2011. A unique genotype of Leptospira interrogans serovar Pomona type kennewicki is associated with equine abortion. Vet. Microbiol. 150, 349353. doi:http://dx.doi.org/10.1016/j.vetmic.2011.02.049.

Vieira, M.L., de Morais, Z.M., Vasconcellos, S.A., Romero, E.C., Nascimento, A.L.T.O., 2011. In vitro evidence for immune evasion activity by human plasmin associated to pathogenic Leptospira interrogans. Microb. Pathog. 51, 360-365. doi:http://dx.doi.org/10.1016/j.micpath.2011.06.008. 